\title{
CD7 in acute myeloid leukemia: correlation with loss of wild-type CEBPA, consequence of epigenetic regulation
}

\author{
Sonja Röhrs' ${ }^{1}$ Michaela Scherr², Julia Romani', Margarete Zaborski' ${ }^{1}$ Hans G Drexler ${ }^{1}$ and Hilmar Quentmeier*1
}

\begin{abstract}
Background: $C D 7$ is a negative prognostic marker in myeloid malignancies. In acute myeloid leukemia (AML), an inverse correlation exists between expression of wild-type CEBPA and CD7. Aim of this study was to find out whether C/ EBPa is a negative regulator of CD7 and which other regulatory mechanisms might be involved.

Results: As already described for primary AML cells, the majority of AML cell lines tested were either C/EBPa+/CD7- or

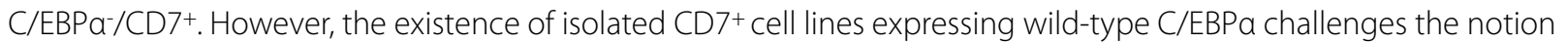
that $C / E B P a$ acts as a unique repressor of CD7. Furthermore, ectopic expression of CEBPA did not reduce CD7 in CD7+ cells and knock-down of C/EBPa failed to induce CD7 in CD7- cells. In contrast, the DNA demethylating agent Aza2'deoxycytidine triggered CD7 expression in CD7- AML and in T-cell lines suggesting epigenetic regulation of CD7. Bisulfite sequencing data confirmed that CpGs in the CD7 exon1 region are methylated in CD7-cell lines, and unmethylated in $\mathrm{CD} 7+$ cell lines.

Conclusion: We confirmed an inverse correlation between the expression of wild-type CEBPA and of CD7 in AML cells. Our results contradict the hypothesis that C/EBPa acts as repressor for CD7, and instead show that epigenetic mechanisms are responsible for CD7 regulation, in AML cells as well as in T-cells, the typical CD7 expressing cell type.
\end{abstract}

\section{Background}

CCAAT/enhancer binding factor alpha (CEBPA), located on chromosome 19q13.1 encodes a transcription factor that is of importance for granulocytic differentiation [1]. $\mathrm{C} / \mathrm{EBP} \alpha$ is upregulated during myelomonocytic development and positively affects expression of granulocyte differentiation related genes such as the G-CSF receptor (GCSFR), myeloperoxidase and neutrophil elastase (ELA2) [2-4]. CEBPA mutations are found in $5-14 \%$ of acute myeloid leukemia (AML) cases [5]. C/EBP $\alpha$ mutant proteins block the effect of wild-type $\mathrm{C} / \mathrm{EBP} \alpha$ on target genes in a dominant-negative manner [6]. This might be the reason why patients with $C E B P A$ mutations and those with a silenced $C E B P A$ promoter are found in the same AML subclass according to gene expression profiling [7]. Also expression of the T-cell marker $C D 7$ has been asso-

\footnotetext{
* Correspondence: hqu@dsmz.de

${ }^{1}$ DSMZ-German Collection of Microorganisms and Cell Cultures, Braunschweig, Germany

Full list of author information is available at the end of the article
}

ciated with CEBPA mutations and with CEBPA hypermethylation $[7,8]$.

CD7 is expressed in $30 \%$ of AML cases and CD7 positivity is linked with poor prognosis in myeloid malignancies $[9,10]$. In healthy individuals, CD7 is expressed on thymocytes, $\mathrm{T}$ - and natural killer cells, and progenitors of lymphoid and myeloid cells [10]. Conditional knockout experiments in mice suggest that Cebpa is involved in the regulation of $\mathrm{Cd} 7$ expression: absence of Cebpa results in upregulation of $\mathrm{Cd} 7$ in mouse hematopoetic stem cells, reintroduction of the transcription factor reduces expression of $C d 7$ [7].

We wanted to find out whether CD7 positivity in AML can be explained as consequence of loss or inactivation of wild-type CEBPA. Therefore, we externally regulated CEBPA expression in AML cell lines and tested whether and how this treatment affected $C D 7$ expression.

@ 2010 Röhrs et al; licensee BioMed Central Ltd. This is an Open Access article distributed under the terms of the Creative Commons B.Wed Central Attribution License (http://creativecommons.org/licenses/by/2.0), which permits unrestricted use, distribution, and reproduction in any medium, provided the original work is properly cited. 


\section{Results and discussion}

\section{CEBPA expression and CD7 silencing}

Quantitative real-time PCR (qRT-PCR) analysis showed that $42 \%(23 / 54)$ of the AML cell lines tested were CD7 positive with expression levels comparable to those of $\mathrm{T}$ cell lines, 28\% (15/54) of cell lines were weakly positive and $30 \%(16 / 54)$ were $C D 7$ negative.

On the first view, Western blot analyses confirmed that $\mathrm{C} / \mathrm{EBP} \alpha$ might be a negative regulator for $C D 7$ expression in AML cell lines: most cell lines showed mutually exclusive expression of these proteins, being either $\mathrm{C} / \mathrm{EBP}^{+} /$ CD7 - or $\mathrm{C} / \mathrm{EBP} \alpha-\mathrm{CD}^{+}+$(Fig. 1A, Table 1). However, there was one noticeable exception: cell line HNT-34 expressed both proteins, $\mathrm{C} / \mathrm{EBP} \alpha$ and $\mathrm{CD} 7$, challenging the automatic linkage of $\mathrm{C} / \mathrm{EBP} \alpha$ expression to $C D 7$ repression (Fig. 1A, Table 1).

Furthermore, it remained open as to how the transcription factor C/EBP $\alpha$ could inhibit expression of $C D 7$. The search for transcription factor binding sites using bioinformatic databases (TFSEARCH and TESS) did not reveal a potential C/EBP $\alpha$ binding site in the $C D 7$ promoter region $(-713$ to +624$)$. A report describing that $c$ -

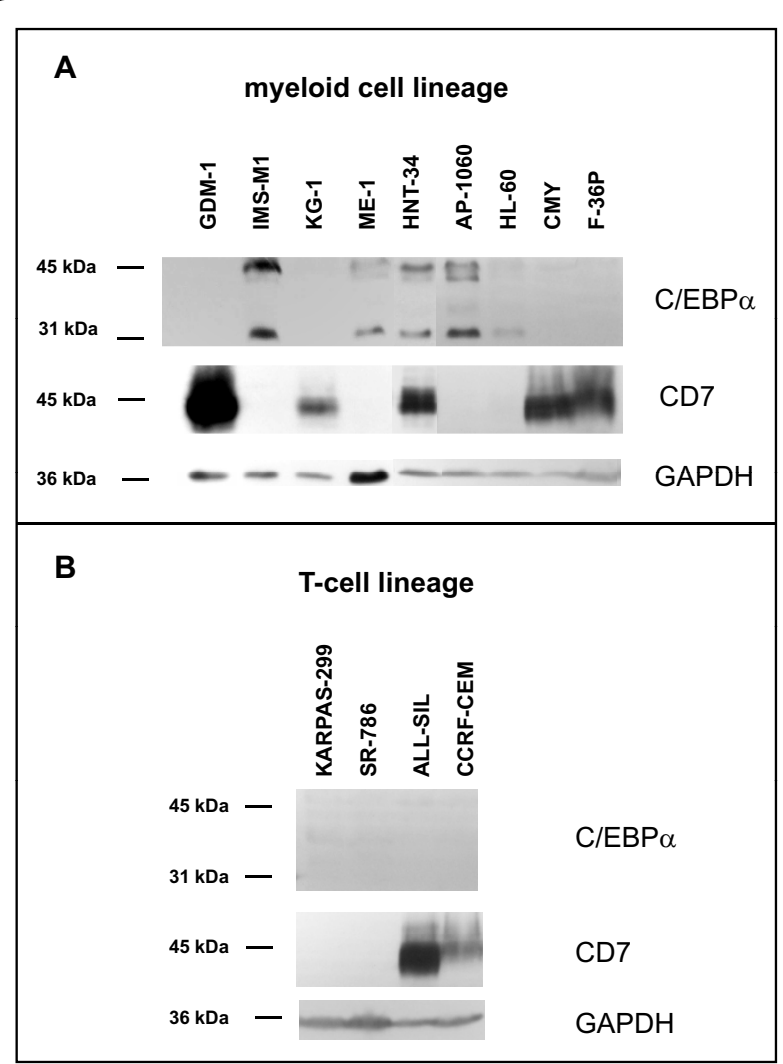

Figure 1 C/EBPa and CD7 protein expression. Western blot analyses were performed to detect C/EBPa and CD7 in (A) AML cell lines and in (B) T-cell lines. GAPDH was used as protein loading control. Note that the AML cell line HNT-34 expresses C/EBPa and CD7 and that T-cell lines can be $\mathrm{C} / \mathrm{EBPa}^{-} / \mathrm{CD} 7$.
$M y c$ expression was negatively regulated by $\mathrm{C} / \mathrm{EBP} \alpha$ via an E2F binding site [11] indicates the possibility of a $\mathrm{C} /$ $\mathrm{EBP} \alpha$-mediated transcriptional gene regulation by protein/protein interaction. $C D 7$ exon 1 also contains an E2F binding site according to TFSEARCH results. To test whether $\mathrm{C} / \mathrm{EBP} \alpha$ acts as direct or indirect transcriptional repressor for $C D 7$ - by protein/DNA or by protein/protein interaction - we checked our cell lines for any $\mathrm{C} /$ $\mathrm{EBP} \alpha / C D 7 \mathrm{mRNA}$ correlation. Analysis of C/EBP $\alpha$ protein and $C D 7$ mRNA expression showed an even weaker correlation than the protein/protein analysis: $3 / 25$ cell lines (HNT-34, IMS-M1, ME-1) were C/EBP $\alpha$-positive and still showed high expression levels of $C D 7$ mRNA (Table 2).

We sequenced the CEBPA gene to find out whether $C D 7$ expression in these three cell lines might result from inactivating CEBPA mutations. Two of the three $\mathrm{C} /$ $\mathrm{EBP} \alpha^{+} / C D 7^{+}$cell lines (HNT-34, IMS-M1) carried and expressed an in-frame CEBPA mutation resulting in four (instead of three) histidine-proline repeats in the transactivation domain 2 of the protein. However, this mutation is considered insignificant for leukemogenesis as it was detected in $39 \%$ of healthy volunteers and in $20 \%$ of AML patients who remained positive after complete remission [8]. Accordingly, 7/25 (28\%) cell lines in our study carried this length polymorphism. Sequencing revealed that none of the three C/EBP $\alpha$ positive and $C D 7$ mRNA positive cell lines showed an inactivating CEBPA aberration. Furthermore, cell line ME-1 did not carry any mutation at all, showing that the $C D 7$ gene could be transcribed despite expression of wild-type C/EBP $\alpha$.

\section{No direct influence of C/EBPa on expression of CD7}

We had started this project to find out whether CD7 positivity in AML might be due to loss or inactivation of wild-type $C E B P A$. In line with the idea of a repressor function for $C / E B P \alpha$ was the observation that most cell lines showed an inverse correlation between C/EBP $\alpha$ and CD7 expression (Table 2). However, $3 / 25$ cell lines (HNT34, IMS-M1, ME-1) were C/EBP $\alpha^{+}$and still expressed CD7 mRNA. C/EBP $\alpha / C D 7$ double positivity does not necessarily contradict a repressor function of C/EBP $\alpha$. Cell lines HNT-34, IMS-M1 and ME-1 might carry additional genetic or epigenetic alterations not allowing a "normal" repressor function of $\mathrm{C} / \mathrm{EBP} \alpha$ in these cell lines.

To experimentally test whether $\mathrm{C} / \mathrm{EBP} \alpha$ has a direct inhibitory effect on $C D 7$ expression, we first ectopically expressed CEBPA in the $\mathrm{C} / \mathrm{EBP} \alpha^{-} / \mathrm{CD}^{+}+$cell line $\mathrm{CMY}$ and then knocked down $\mathrm{C} / \mathrm{EBP} \alpha$ in the $\mathrm{C} / \mathrm{EBP}^{+} / \mathrm{CD}^{-}$ cell line NB-4 (Table 2). In both cell lines, expression of the transcriptional C/EBP $\alpha$ targets GCSFR and ELA2 was positively correlated with CEBPA expression levels (Fig. 2). In contrast, $C D 7 \mathrm{mRNA}$ levels were neither positively nor negatively affected by C/EBP $\alpha$ (Fig. 2). These results 
Table 1: C/EBPa and CD7 expression in AML cell lines

\begin{tabular}{cccc}
\hline C/EBPa & CD7 neg & CD7 low & CD7 high \\
\hline neg & 0 & 1 & 9 \\
low & 1 & 1 & 1 \\
high & 10 & 1 & 1 \\
\hline
\end{tabular}

Inverse correlation between C/EBPa and CD7 protein expression in $25 \mathrm{AML}$ cell lines as assessed by Western blot analysis. Cell lines classified as "low" showed faint signals, "high" denotes all positive signals in Fig. 1. GAPDH was used as protein loading control. Note that one cell line (HNT-34) expressed C/EBPa (high) and CD7 (high).

contradict the hypothesis that $\mathrm{C} / \mathrm{EBP} \alpha$ acts as $C D 7$ suppressor.

\section{Epigenetic regulation of CD7}

Study of T-cell lines confirmed that $C D 7$ repression can occur in the absence of $\mathrm{C} / \mathrm{EBP} \alpha$ : T-cell lines are $\mathrm{C} / \mathrm{EBP} \alpha$ - negative, but not all T-cell lines express CD7 (Fig. 1B). The CD7 promoter region does not match the criteria of a standard $\mathrm{CpG}$ island with a GC content $>50 \%$ and an observed CpG/expected CpG ratio > 0.6 [12]. However, according to the criteria of Weber et al. [13] the CD7 exon 1 region contains a subthreshold CpG island (inter-

Table 2: C/EBPa and CD7 expression in individual AML cell lines

\begin{tabular}{|c|c|c|c|c|}
\hline Cell lines & CEBPA mRNA & C/EBPa protein & CD7 mRNA & CD7 protein \\
\hline AP-1060 & + & + & - & - \\
\hline CMK & $(+)$ & - & + & + \\
\hline CMY & - & - & + & + \\
\hline$F-36 P$ & - & - & + & + \\
\hline GDM-1 & $(+)$ & - & + & + \\
\hline HL-60 & + & + & - & - \\
\hline HNT-34 & + & + & + & + \\
\hline HT-93A & + & + & - & - \\
\hline IMS-M1 & + & + & + & - \\
\hline KG-1 & $(+)$ & - & + & + \\
\hline M-07e & - & - & + & + \\
\hline ME-1 & + & + & + & - \\
\hline MEGAL & $(+)$ & - & + & + \\
\hline MOLM-16 & - & - & + & + \\
\hline MONO-MAC-6 & + & + & $(+)$ & - \\
\hline MUTZ-8 & + & + & $(+)$ & $(+)$ \\
\hline NB-4 & + & + & - & - \\
\hline OCI-AML2 & + & + & - & - \\
\hline OCI-AML5 & + & + & - & - \\
\hline OCI-M1 & $(+)$ & $(+)$ & - & $(+)$ \\
\hline $\mathrm{OCl}-\mathrm{M} 2$ & $(+)$ & - & - & $(+)$ \\
\hline SET-2 & $(+)$ & $(+)$ & + & + \\
\hline SIG-M5 & + & + & - & - \\
\hline SKNO-1 & $(+)$ & $(+)$ & $(+)$ & - \\
\hline TF-1 & - & - & + & + \\
\hline
\end{tabular}

C/EBPa and CD7 Western blot analysis: + positive, (+) weakly positive, - negative. GAPDH was used as protein loading control. CEBPA qRT-PCR: $+: 2^{\wedge}-\Delta \Delta \mathrm{ct} \geq 5.0 ;(+) 2^{\wedge}-\Delta \Delta \mathrm{ct} \geq 0.2,<5.0 ;-: 2^{\wedge}-\Delta \Delta \mathrm{ct}<0.2$. The CEBPA-low cell line SET-2 was used as calibrator cell line. CD7 qRT-PCR: $+: 2^{\wedge}-$ $\Delta \Delta \mathrm{ct}>2.5 ;(+) 2 \wedge-\Delta \Delta \mathrm{ct} \geq 1 ;-: 2^{\wedge}-\Delta \Delta \mathrm{ct}<1$. The CD7-low cell line MUTZ-8 was used as calibrator cell line. Note that cell lines HNT-34, IMS-M1 and ME-1 (bold) express C/EBPa and CD7 mRNA. 


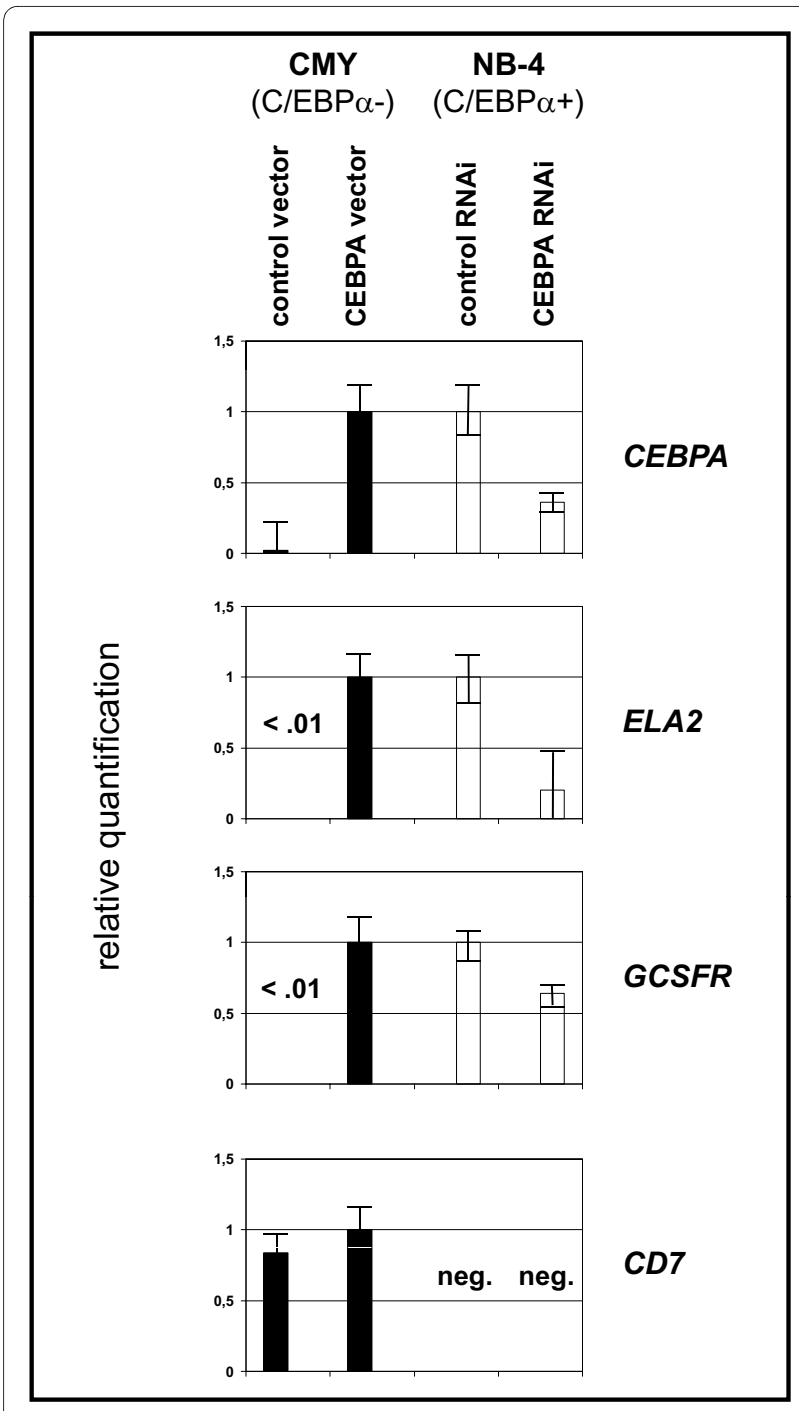

Figure $\mathbf{2}$ C/EBPa does not affect CD7 mRNA expression. CEBPA was ectopically expressed in the CEBPA-negative cell line CMY and repressed in the CEBPA-positive cell line NB-4. Expression levels were assessed at day 4 (CEBPA RNAi) and day 13 (ectopic expression of CEBPA) by qRT-PCR. Gene names at the right-hand side of the figure apply for all four columns. Expression of the C/EBPa targets ELA2 and GCSFR depends on CEBPA expression, CD7 mRNA levels are unaffected and remain positive in cell line CMY, negative (neg.) in cell line NB-4.

mediate $\mathrm{CpG}$ promoter) with moderate $\mathrm{CpG}$ richness (observed $\mathrm{CpG} /$ expected $\mathrm{CpG}$ ratio > 0.2) and high GC content $(>60 \%)$ suggesting that the gene might be epigenetically regulated. Methylation-specific PCR (MSP) and sequencing of bisulfite-converted DNA revealed that this site was methylated in CD7-negative T-cell lines, while CD7-positive T-cell lines were not methylated around the transcriptional start site (Fig. 3, 4). These data support a recent study linking $C D 7$ expression to chromatin modifications in CML [14]. Also in AML, unmethylated cell lines (unmethylated signal $U$ only) expressed $C D 7(2 / 2)$,

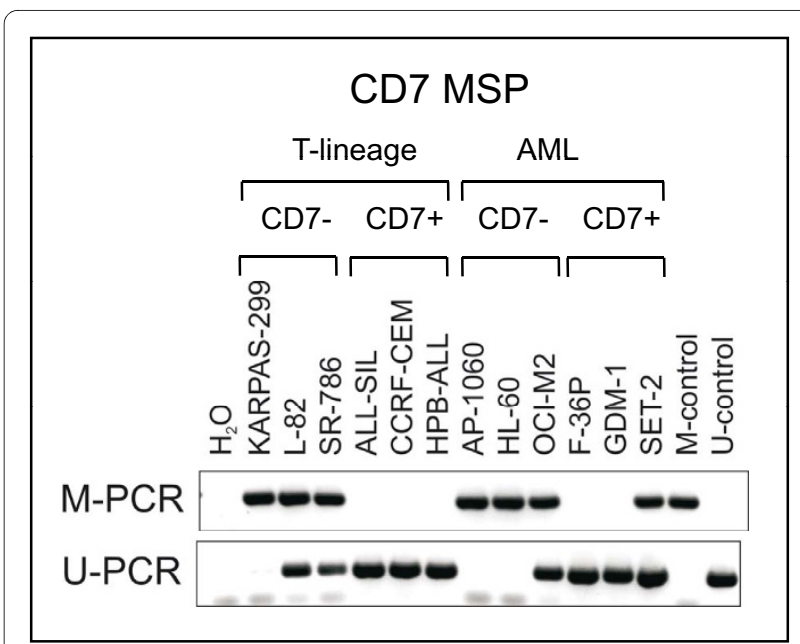

Figure 3 Epigenetic regulation of $C D 7$. CD7 promoter methylation was analyzed by MSP after bisulfite conversion of the DNA. Agarose gels of CD7 M- and U-PCR products from T- and AML cell lines are shown as representative results.

while methylated cell lines (methylated signal $\mathrm{M}$ only) were $C D 7$-negative (8/9) or weakly positive (1/9) (Table 3). Furthermore, a DNA demethylating agent induced $C D 7$ expression in CD7-methylated cell lines, independent of histological origin: the T-anaplastic large cell lymphoma-derived cell line SR-786 and the AML cell line HL-60 each showed a ca. 30 -fold increase of CD7 expression after treatment with 5-Aza-2'-deoxycytidine (Aza), while unmethylated cell lines (ALL-SIL, F-36P, GDM-1) were unaffected (Fig. 4). These results suggest that epigenetic mechanisms play a role in the regulation of $C D 7$, both in T-cell lines and in AML cell lines: (i) we found a negative correlation between $C D 7$ promoter methylation and gene expression, and (ii) observed that a demethylating agent induced $C D 7$ expression in silenced cell lines.

Interestingly four cell lines (IMS-M1, ME-1, MONOMAC-6, SKNO-1) were CD7 mRNA positive but did not express CD7 protein (Table 2). Future studies might show which posttranscriptional mechanisms - including possibly translational inhibition by microRNAs - are responsible for this phenomenon.

\section{Conclusions}

An inverse correlation between $C D 7$ methylation and CD7 expression was observed in T-cell lines as well as in AML cell lines suggesting that in both lineages epigenetic mechanisms underlie $C D 7$ regulation. Two observations imply that other factors are also important for $C D 7$ expression: (i) the stimulating effect of Aza on $C D 7$ expression levels varied substantially across different CD7 methylated cell lines, and (ii) even cell lines that were clearly responsive to Aza with respect to $C D 7$ mRNA induction did not show upregulation of $\mathrm{CD} 7$ pro- 


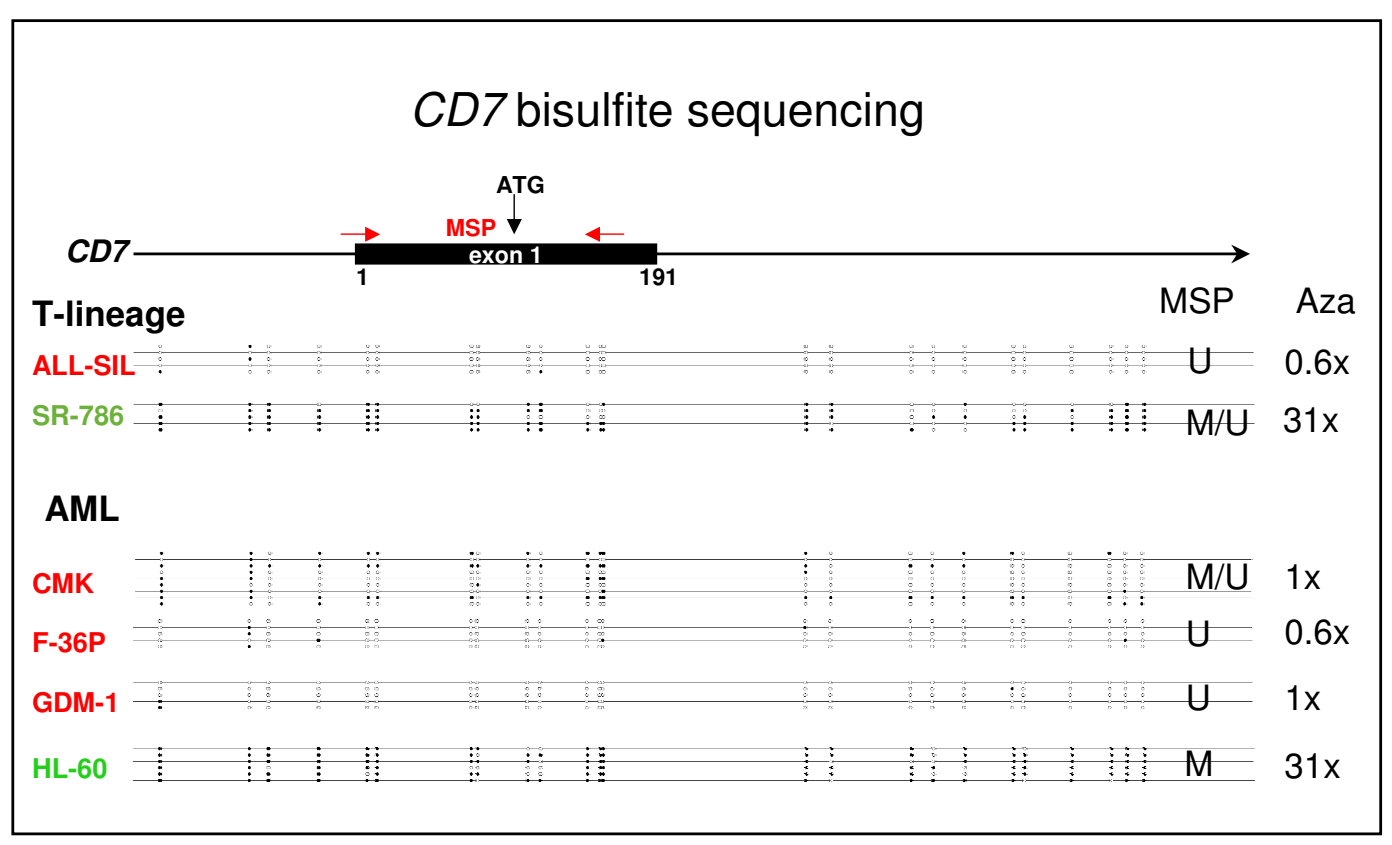

Figure 4 Bisulfite sequencing of $C D 7$ exon 1 region. $C p G s$ are represented as open dots $(U=$ unmethylated) or filled dots $(M=$ methylated). Name in red: $C D 7+$ cell line, name in green: $C D 7$ - cell line. Numbers on the right hand side show the effect of Aza (3 d, $5 \mu M$ ) on CD7 mRNA levels, as assessed by qRT-PCR. Note that Aza induces CD7 expression in methylated cell lines (SR-786 and HL-60) only.

tein as assessed by Western blot and FACS analysis (data not shown). Although transfection studies did not indicate that $\mathrm{C} / \mathrm{EBP} \alpha$ acts as $C D 7$ repressor, the inverse correlation between $C E B P A$ and $C D 7$ expression reported for primary AML cases was confirmed for most AML cell lines. Thus, future studies should address whether $\mathrm{C} /$ $\mathrm{EBP} \alpha$ is a second factor responsible for repression of $C D 7$ besides promoter methylation.

\section{Methods}

Human cell lines

The continuous cell lines were either taken from the stock of the cell bank (DSMZ - German Collection of Microorganisms and Cell Cultures) or were generously provided by the original investigators. Detailed references and cultivation protocols have been described previously [15].

\section{Methylation-specific polymerase chain reaction (MSP)}

Bisulfite conversion of DNA was performed as described by the supplier (EpitTect Bisulfite Kit, Qiagen, Hilden, Germany). For detecting $C D 7$ promoter methylation, we performed nested PCR with first round primers $(C D 7$ BSP fwd 5'-TTT TGT GGA GAT GTA GGG GTA-3', CD7 BSP rev 5'-CAC CAT CAA TCT AAC CAA AAA AAC-3') amplifying converted DNA independently of the methylation status (bisulfite-specific PCR, BSP), while second round primers (CD7 $\mathrm{M}$ fwd 5'-TTT TTG AGT TTT GAG CGT TTG C-3', CD7 M rev 5'-AAA CAA ACC GCG AAC CAA CG-3', CD7 U fwd 5'-GTT TTT

Table 3: CD7 promoter methylation and CD7 mRNA expression in AML cell lines

\begin{tabular}{cccc}
\hline CD7 MSP & CD7 mRNA negative & CD7 mRNA low & \\
\hline U & 0 & 0 & 2 \\
U/M & 1 & 1 & 0
\end{tabular}

$C D 7$ methylation was assessed by MSP. $\mathrm{U}$ : products with primers recognizing unmethylated $C D 7$ only; $\mathrm{U} / \mathrm{M}: \mathrm{U}$ and $\mathrm{M}$ (methylated) products; M: M products only. CD7 mRNA expression was assessed by qRT-PCR and evaluated as described in Table 2 . Note that $2 / 2$ unmethylated (U only) cell lines are CD7-positive and that $8 / 9$ methylated ( $M$ only) cell lines are CD7-negative. Methylation-specific ( $M$ ) and unmethylationspecific (U) PCR were very sensitive, allowing the detection of one methylated cell in 1000 unmethylated cells and vice versa. Therefore, a meaningful correlation between $C D 7$ methylation and expression was not apparent in U/M cells. 
TTT GAG TTT TGA GTG TTT GT-3', CD7 U rev 5'CCA AAC AAA CCA CAA ACC AAC A-3') for M- and U-PCR specifically recognized the methylated or unmethylated versions of the promoter. PCR products of the initial BSP were diluted 1:100 for subsequent M- and UPCR. Annealing temperatures were $53^{\circ} \mathrm{C}$ for BSP with 35 cycles and $63^{\circ} \mathrm{C}$ for $\mathrm{M}$ - and U-PCR with 30 cycles each. Epitect PCR Control DNA (Qiagen) was used as control for methylated and unmethylated templates.

\section{Bisulfite sequencing}

To confirm the methylation status of the $C D 7$ promoter, DNA of cell lines was bisulfite converted according to the manufacturer's instructions (Qiagen). Subsequently, amplification of the $C D 7$ exon 1 region $(760 \mathrm{bp})$ was performed using primers $C D 7$ BSP fwd and CD7 BSP rev, specifically binding bisulfite converted DNA (for primer sequence and PCR conditions see MSP section). Resulting $C D 7$ fragments were purified, cloned into pGEMTEasy vector (Promega, Madison, WI, USA) and sequenced. Sequences were evaluated using BiQ Analyzer http://biq-analyzer.bioinf.mpi-sb.mpg.de and had to conform to at least $90 \%$ bisulfite conversion rate [16]. In addition, identical clones were excluded from the analysis.

\section{Gene expression analyses}

Quantitative PCR was performed on a 7500 Applied Biosystems (Darmstadt, Germany) real-time PCR system using the manufacturer's protocol. RNA was prepared using the RNeasy Mini kit (Qiagen). For mRNA quantification, reverse transcription was performed using the SuperScript II reverse transcriptase kit (Invitrogen, Karlsruhe, Germany). TaqMan probes (Applied Biosystems) were used to quantify human CEBPA (Hs 00269972s1), ELA2 (Hs $00357734 \mathrm{~m} 1$ ) and GCSFR (Hs $01114427 \mathrm{~m} 1$ ) expression levels with $T B P$ as endogenous control. Expression of $C D 7$ was assessed using the SYBR GREEN PCR Master Mix (Applied Biosystems) with GAPDH as internal control. $C D 7$ forward: 5'-GTG CTG GCG AGG ACA CAG-3'; CD7 reverse: 5'-TCG TAC ACC ACA CAT GCC G-3'. GAPDH forward: 5'-TGG GTG TGA ACC ATG AGA AG-3'; GAPDH reverse: 5'TCC ACG ATA CCA AAG TTG TCA-3'. Relative expression levels were calculated using the $\Delta \Delta \mathrm{Ct}$-method.

\section{Treatment with DNA demethylating agent Aza}

5-Aza-2'-deoxycytidine (Aza) (Sigma) dissolved in DMSO was used to verify the effect of methylation on expression of $C D 7$. Cells were seeded at a cell density of 5 $\times 10^{5} \mathrm{cells} / \mathrm{ml}$, Aza was added at a final concentration of 5 $\mu \mathrm{M}$. Control cells were treated with $0.05 \%$ DMSO. After 2 $\mathrm{d}$, half of the medium was replenished with medium with/without Aza ( $5 \mu \mathrm{M})$. After $3 \mathrm{~d}$, respectively $4 \mathrm{~d}$, cells were harvested to prepare RNA or protein.

\section{Western blot analysis}

Samples were prepared as described previously [17]. Anti CD7 antiserum was purchased from Santa Cruz (Heidelberg, Germany), anti C/EBPa antiserum was obtained from Cell Signaling/New England Biolabs (Frankfurt, Germany). Specific bands on nitrocellulose membranes were visualized with the biotin/streptavidin-horseradish peroxidase system (Amersham, Freiburg, Germany) in combination with the "Renaissance Western Blot Chemoluminescence Reagent" protocol (DuPont, Bad Homburg, Germany).

\section{Bioinformatic database search for C/EBPa binding sites}

The genomic sequence of the $C D 7$ promoter region from -713 to +624 was analyzed with the database search tools TFSEARCH ver.1.3 http://www.cbrc.jp/research/db/ TFSEARCH.html and TESS http://www.cbil.upenn.edu/ cgi-bin/tess/tess for the existence of potential C/EBP $\alpha$ binding sites (Factor ID in TESS: T00105).

\section{Plasmid construction}

For generating the anti-CEBPA shRNA, DNA oligonucleotides corresponding to position 818-836 of the sequence of the human CEBPA gene (GenBank accession no. NM 004364.3) were subjected to BLAST homology search, and thereafter chemically synthesized including overhang sequences from a 5'-BglII and a 3'-SalI restriction site for cloning purposes (BioSpring, Frankfurt, Germany). The numbering of the first nucleotide of the shRNA refers to the ATG start codon. The oligonucleotide sequences were as follows: FPCEBPA: 5'GATCCCCGGCCAAGAAGTCGGTGGACTTCAAGA GAGTCCACCGACTTCTTGGCCTTTTTTGGAAG-3'; RPC EBPA: 5'-CGACTTCCAAAAAAGGCCAAGAAGTCG GTGGACTCTCTTGAAGTCCACCGACTTCTTGGCCGGG-3'.

The non-complementary 9-nt loop sequences are underlined, and each sense oligonucleotide harbors a stretch of $\mathrm{T}$ as a PolIII transcription termination signal. The oligonucleotides were annealed and inserted 3 ' of the H1-RNA promoter into the BglII/SalI-digested pBlueScript-derived pH1-plasmid to generate $\mathrm{pH} 1-C E B P A$ as described [18]. The control plasmid pH1-GL4 has been described earlier [18]. Finally, the H1-CEBPA expression cassette was excised by digestion with SmaI and HincII and blunt-end ligated into the SnaBI site of the pdc-SR lentiviral vector to generate pdcH1-CEBPA-SR plasmid. The lentiviral plasmid encodes $\mathrm{RFP}_{\text {EXPRESS }}$ as reporter gene. 


\section{Preparation of recombinant lentiviral supernatants and lentiviral transduction}

Preparation of recombinant lentiviral supernatants and transduction were performed as described previously [18]. The titers were averaged and typically ranged between $5-10 \times 10^{8} \mathrm{IU} / \mathrm{ml}$. Concentrated viral supernatants were used for transduction of NB-4 cells in 48-well plates as described [18].

\section{Competing interests}

The authors declare that they have no competing interests.

\section{Authors' contributions}

SR designed parts of the study and performed MSP analysis, sequencing of bisulfite-converted DNA and co-wrote the manuscript, MS performed knockdown and expression experiments, JR performed Western blot analysis, MZ performed quantitative real-time PCR, HGD provided cell lines and critically read the manuscript, $\mathrm{HQ}$ designed the study and wrote the manuscript. All authors read and approved the final manuscript.

\section{Acknowledgements}

We thank Beatrice Mueller and Thomas Pabst (University Hospital Bern, Switzerland) for providing CEBPA plasmid, and Rod MacLeod for critically reading the manuscript.

\section{Author Details}

'DSMZ-German Collection of Microorganisms and Cell Cultures, Braunschweig, Germany and 2Department of Hematology, Hemostasis, Oncology and Stem Cell Transplantation, Medical School Hannover, Hannover, Germany

Received: 8 March 2010 Accepted: 14 April 2010

Published: 14 April 2010

\section{References}

1. Radomska HS, Huettner CS, Zhang P, Cheng T, Scadden DT, Tenen DG CCAAT/Enhancer binding protein alpha is a regulatory switch sufficient for induction of granulocytic development from bipotential myeloid progenitors. Mol Cell Biol 1998, 18:4301-4314.

2. Smith LT, Hohaus S, Gonzalez DA, Dziennis SE, Tenen DG: PU.1 (Spi-1) and C/EBPa regulate the granulocyte colony-stimulating factor receptor promoter in myeloid cells. Blood 1996, 88:1234-1247.

3. Iwama A, Zhang P, Darlington GJ, McKercher SR, Maki R, Tenen DG: Use of RDA analysis of knockout mice to identify myeloid genes regulated in vivo by PU.1 and C/EBPa. Nucleic Acids Res 1998, 26:3034-3043.

4. Oelgeschläger M, Nuchprayoon I, Lüscher B, Friedman AD: C/EBP, c-Myb, and PU.1 cooperate to regulate the Neutrophil Elastase Promoter. $\mathrm{Mol}$ Cell Biol 1996, 16:4717-4725.

5. Mueller BU, Pabst T: C/EBPa and the pathophysiology of acute myeloid leukemia. Curr Opin Hematol 2006, 13:7-14.

6. Pabst T, Mueller BU, Zhang P, Radomska HS, Narravula S, Schnittger S, Behre G, Hiddemann W, Tenen DG: Dominant-negative mutations of CEBPA, encoding CCAAT/enhancing binding protein-a (C/EBPa), in acute myeloid leukemia. Nature Genet 2001, 27:263-270.

7. Wouters BJ, Jordà MA, Keeshan K, Louwers I, Erpelinck-Verschueren CAJ, Tielemans D, Langerak AW, He Y, Yashiro-Ohtani Y, Zhang P, Hethereington CJ, Verhaak RGW, Valk PJM, Löwenberg B, Tenen DG, Pear WS, Delwel R: Distinct gene expression profiles of acute myeloid/Tlymphoid leukemia with silenced CEBPA and mutations in NOTCH1. Blood 2007, 110:3706-3714.

8. Lin LI, Chen CY, Lin DT, Tsay W, Tang JL, Yeh YC, Shen HL, Su FH, Yao M, Huang SY, Tien HF: Characterization of CEBPA mutations in acute myeloid leukemia: most patients with CEBPA mutations have biallelic mutations and show a distinct immunophenotype of the leukemic cells. Clin Cancer Res 2005, 11:1372-1379.

9. Chang H, Salma F, Yi Q, Patterson B, Brien B, Minden MD: Prognostic relevance of immunophenotyping in 379 patients with acute myeloid leukemia. Leukemia Res 2004, 28:43-48.
10. Satoh C, Tamura H, Yamashita T, Tsuji T, Dan K, Ogata K: Aggressive characteristics of myeloblasts expressing CD7 in myelodysplastic syndromes. Leukemia Res 2009, 33:326-331.

11. Johansen LM, Iwama A, Lodie TA, Sasaki K, Felsher DW, Golub TR, Tenen DG: c-Myc is a critical target for C/EBPa in granulopoiesis. Mol Cell Biol 2001, 21:3789-3806.

12. Gardiner-Garden $\mathrm{M}$, Frommer $\mathrm{M}: \mathrm{CpG}$ islands in vertebrate genomes. $J$ Mol Biol 1987, 162:261-282.

13. Weber M, Hellmann I, Stadler MB, Ramos L, Pääbo S, Rebhan M, Schübeler $D$ : Distribution, silencing potential and evolutionary impact of promoter DNA methylation in the human genome. Nature Genetics 2007, 39:457-466

14. Rogers SL, Zhao Y, Jiang X, Eaves CJ, Mager DL, Rouhi A: Expression of the leukemic prognostic marker CD7 is linked to epigenetic modifications in chronic myeloid leukemia. Mol Cancer 2010, 9:41.

15. Drexler HG: Guide to Leukemia-Lymphoma Cell Lines Braunschweig; 2005.

16. Bock C, Reither S, Mikeska T, Paulsen M, Walter J, Lengauer T: BiQ analyser: visualization and quality control for DNA methylation data from bisulfite sequencing. Bioinformatics 2005, 21:4067-4068.

17. Quentmeier H, Schneider B, Röhrs S, Romani J, Zaborski M, MacLeod RAF, Drexler HG: SET-NUP214 fusion in acute myeloid leukemia- and T-cell acute lymphoblastic leukemia-derived cell lines. J Hematol Oncol 2009, 2:3.

18. Scherr M, Battmer K, Ganser A, Eder M: Modulation of gene expression by lentiviral-mediated delivery of small interfering RNA. Cell Cycle 2003, 2(3):251-257.

doi: 10.1186/1756-8722-3-15

Cite this article as: Röhrs et al., CD7 in acute myeloid leukemia: correlation with loss of wild-type CEBPA, consequence of epigenetic regulation Journal of Hematology \& Oncology 2010, 3:15

\section{Submit your next manuscript to BioMed Central} and take full advantage of:

- Convenient online submission

- Thorough peer review

- No space constraints or color figure charges

- Immediate publication on acceptance

- Inclusion in PubMed, CAS, Scopus and Google Scholar

- Research which is freely available for redistribution
C Biomed Central 